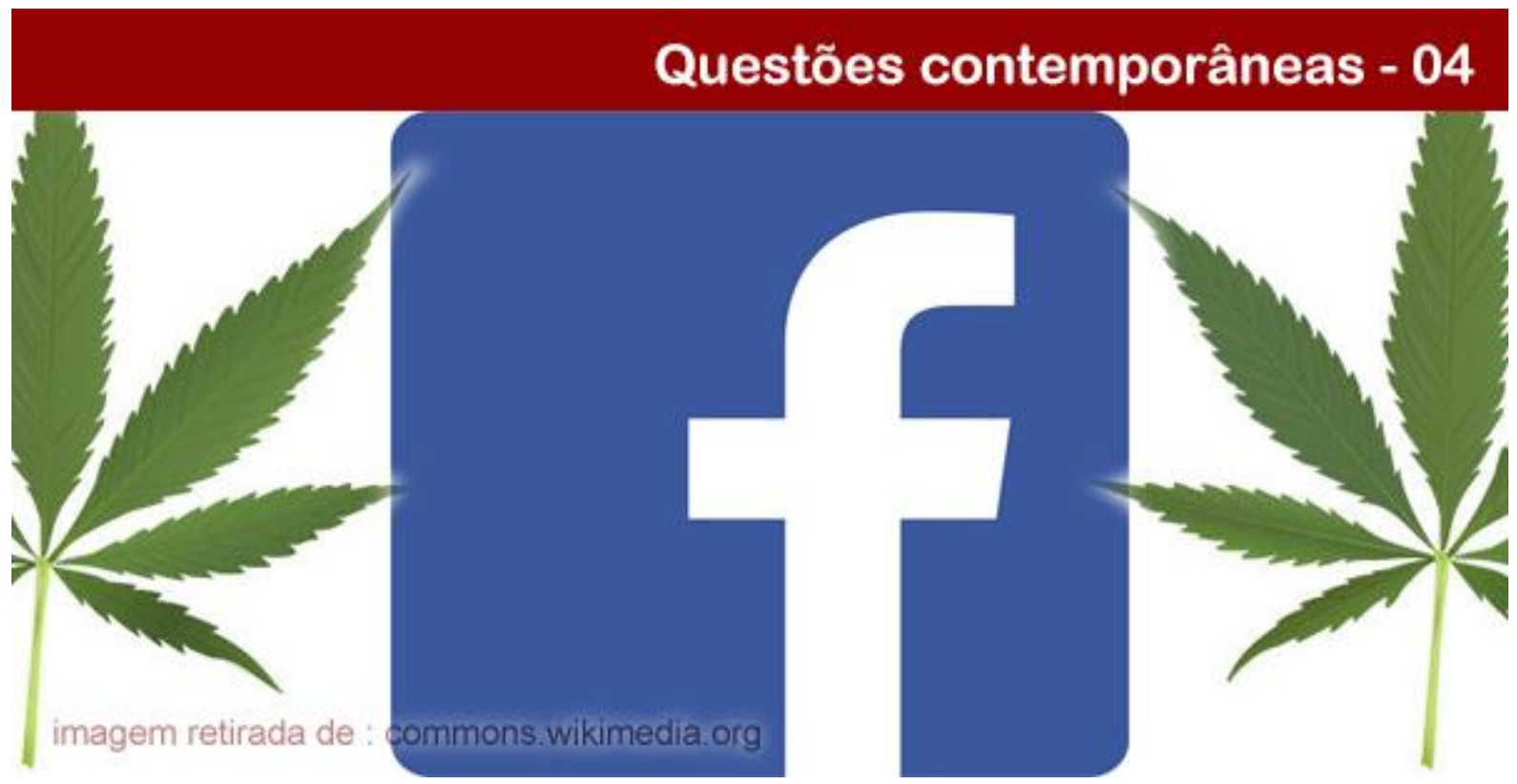

\title{
INFORMAÇÃO OU RIVALIDADE? SOBRE O USO DE PESQUISAS CIENTÍFICAS EM DISCUSSÕES SOBRE A MACONHA E O THC NO FACEBOOK
}

\author{
Carolina Alves Ieda \\ Psicóloga. Mestranda em Psicologia pela Universidade Federal de Mato Grosso (UFMT). E-mail: \\ carolinaieda.ci@gmail.com.
}

Resumo: O uso e distribuição da maconha no Brasil podem ser considerados como um assunto recorrente em discussões nas redes sociais, atualmente. Porém, a discussão acerca da maconha não é um assunto recente, podendo remontar ao Brasil colônia. Neste trabalho, propõe-se discutir os usos do papel da ciência enquanto um discurso capaz de participar ativamente nesse debate. Duas postagens de páginas com orientações ideológicas opostas serão analisadas a partir da Análise do Discurso junto à noção de Frases Sem Texto, proposto por Dominique Maingueneau. A partir da psicanálise, as relações virtuais serão pensadas como espaços carregados de afeto e significações, compreendidos como um local onde a agressividade também se faz presente. Ao final, destacam-se os usos possíveis de resultados e pesquisas sobre a maconha e THC nas postagens analisadas, evidenciando as oposições e rivalidades que dificultam o diálogo acerca do uso da maconha no Brasil.

Palavras-chave: Psicanálise. Análise do Discurso. Redes Sociais. Maconha.

\section{INFORMATION OR RIVALITY? THE USE OF SCIENTIFIC RESEARCH IN DISCUSSIONS ABOUT MARIJUANA AND THC ON FACEBOOK}

\begin{abstract}
The use and distribution of marijuana in Brazil can be considered as a recurring subject in discussions in social networks, currently. However, the discussion about marijuana is not a recent issue, and can be traced back to Brazil colony. In this paper, it is proposed to discuss the uses of the role of science as a discourse capable of participating actively in this discussion. Two postings of pages with opposing ideological orientations will be analyzed from Discourse Analysis next to the notion of Phrases Without Text, proposed by Dominique Maingueneau. From psychoanalysis, virtual relations will be thought of as spaces full of affection and meaning, understood as a place where aggressiveness is also present. At the end, the possible uses of results and research on marijuana and THC in the analyzed posts are highlighted, evidencing the oppositions and rivalries that make it difficult to have a dialogue about the use of marijuana in Brazil.
\end{abstract}

Keywords: Psychoanalysis. Speech analysis. Social networks. Marijuana.

\section{POLÊM!CA | LABORE (3:}

Polêmica - Revista Eletrônica da Uerj - Rua São Francisco Xavier, 524, $1^{\circ}$ andar bloco D, sl.1001 • Tels.: +55 21 2334-4088/4087 • http://www.e-publicacoes.uerj.br/index.php/polemica/index http://www.labore.uerj.br • laboreuerj@yahoo.com.br 


\section{Introdução}

Nos navios, desde a construção das velas e cordames em fibras de cânhamo, até mesmo no transporte de pessoas escravizadas que chegavam ao país, a história do Brasil está fortemente atrelada à história da maconha (CARLINI, 2006). Dos diversos nomes que recebera: fumo de angola, diamba ou cigarros índios de Grimault, a maconha trazia em si algum apaziguamento psíquico aos laços rompidos no processo de escravatura. Porém, passando por diversas medidas de discussão, controle e combate, a maconha - atualmente - possui o status de droga ilícita perante as instâncias legais (CARLINI, 2006).

A secular perseguição com seus usuários atingiu, historicamente, diversos níveis da vida social incluindo, de forma mais específica, os praticantes de ritos religiosos oriundos da África. Desse modo, os entraves ao cultivo, uso e comércio da maconha não necessariamente se destinaram à droga em si: antes, as estratégias de segregação e estigmatização voltaram-se para populações já afetadas pela desigualdade econômica e pelo racismo. À época,

[...] psiquiatras brasileiros elaboraram uma série de teses criminalizando negros, nativos, mulheres, capoeiristas, sambistas, maconheiros, prostitutas, macumbeiros, cachaceiros, explorando certo tipo de discurso que estigmatizava todos que não fossem supostamente brancos "puros", próximo daquele que viria a originar também ideias fascista e nazista da superioridade de raças. (BARROS; PERES, 2011, p. 13).

Assim, o que se tem, atualmente, como representação legal e constituições imaginárias acerca da maconha, são frutos de um longo processo social que foi capaz de alicerçar as atuais políticas de repressão e criminalização de sua circulação e uso. Os embates discursivos concernentes aos "reais prejuízos e ganhos" são compostos por momentos de duras acusações, através de embasamentos tipificados como científicos.

Nesse texto pretende-se expor alguns dos conflitos presentes em discussões e postagens na rede social Facebook acerca do consumo da maconha e, concomitantemente, das propriedades do THC, que refere-se no vocabulário científico ao D9-tetrahidrocanabinol (D9THC), o principal constituinte psicoativo da cannabis (CRIPPA et al., 2005). O objetivo desse estudo, portanto, se dedica a refletir sobre o uso de pesquisas e falas de representantes da medicina acerca da maconha em duas postagens veiculadas no Facebook, utilizando como método a análise do discurso, mais especificamente, os trabalhos de Dominique Maingueneau (2014). Conjuntamente, a agressividade atrelada aos impulsos destrutivos e o lugar da ciência

\section{POLÊM!CA $\mid$ LABORE}

Polêmica - Revista Eletrônica da Uerj - Rua São Francisco Xavier, 524, $1^{\circ}$ andar bloco D, sl.1001 • Tels.: +55 21 2334-4088/4087 • http://www.e-publicacoes.uerj.br/index.php/polemica/index http://www.labore.uerj.br • laboreuerj@yahoo.com.br 
enquanto fornecedor de balizas capazes de significar as questões humanas será pensado a partir de contribuições psicanalíticas.

Para tanto, a discussão sobre o lugar ocupado pelas redes sociais enquanto um palco capaz de promover encontros e debates é necessária e configura um cuidado sobre as lógicas que regem esses espaços. Ao mesmo tempo em que possibilita a expansão e contato com narrativas diversas, o uso da ferramenta nesse espaço aponta para possíveis formas de amplificação dos conflitos já existentes. Sem desprezar os ganhos trazidos pela internet e seus gadgets, outras faces do ambiente virtual se apresentam em concomitância aos processos positivos verificáveis nas redes sociais. Dessa forma, ao estudar temas relacionados à “internet", mais especificamente, das redes sociais, o assunto demanda manejos capazes de abarcar a complexidade do tema.

\begin{abstract}
O jovem, na cultura contemporânea marcada pela globalização e pelas novas tecnologias de informação, está imerso na imagem. As novas tecnologias da imagem apresentam-se como uma realidade incontestável, fazendo parte do cotidiano das pessoas, funcionando como extensões do homem, que ampliam o seu universo, possibilitando-lhe alcançar outras dimensões, com novos espaços e novos tempos. Mas o computador introduz uma nova modalidade de virtualidade, interativa, constituindo-se, em sua plasticidade, tanto em um local de encontro, criativo e libertador, quanto em um lugar de "desencontro", caótico e aprisionante. (LIMA, 2006, p. 48).
\end{abstract}

\title{
Lugar de afeto, disputas e encontros: a rede social
}

Antes de dar prosseguimento para as análises e discussões, faz-se necessária a observação da rede social enquanto função socialmente produtora de encontros com a alteridade. Que diferença teria esse lugar dos outros contextos de discussão? Do ponto de vista concretual, muitas dissonâncias se traduziriam em diferenças palpáveis entre o ambiente virtual e o "real" (real no sentido comum, devendo ser salientado o uso dessa palavra). Porém, ambos podem ser considerados como ambientes vivenciais, apesar da dessemelhança na concretude sensorial. Fazer compras pela internet, por exemplo, pode possuir efeitos de satisfação tais como a compra presencial, embora tenham diferenças em seus trâmites. Nessa perspectiva, se concebe uma "rede social" como um ambiente dominado pelos conflitos concernentes ao relacionar-se. Essa concepção tomará as redes como um local genuinamente habitado pela ordem dos afetos, não se tratando de um lugar higienizado, destacável do rol de possibilidades das interações humanas. Após ataques acerca da legitimidade do relacionar-se com o outro através de meios virtuais, o contexto e envolvimentos afetivos cultivados pelas redes

\section{POLÊM!CA $\mid$ LABORE}

Polêmica - Revista Eletrônica da Uerj - Rua São Francisco Xavier, 524, $1^{\circ}$ andar bloco D, sl.1001 • Tels.: +55 21 2334-4088 / 4087 • http://www.e-publicacoes.uerj.br/index.php/polemica/index http://www.labore.uerj.br・ laboreuerj@yahoo.com.br 
demonstraram, como a citação abaixo aponta, que toda a gama de sentimentos encontra-se presente nesse meio:

[...] os resultados de inúmeras pesquisas internacionais e nacionais vêm mostrar que esses ambientes se tornaram espaços, análogos aos espaços "reais", nos quais se desenrola o drama sempre real dos relacionamentos pessoais. Encontros, desencontros, paixões, decepções, revelações íntimas acobertadas pelo anonimato protetor dos apelidos (nicks), mentiras, intrigas, traições virtuais, solidariedade, indiferença, etc., todos os ingredientes da sociabilidade tradicional neles passaram a marcar presença. (COSTA, 2005, p. 54).

Dentre os aspectos relacionados aos sentimentos, paixões e tomadas de posição entrelaçados nos espaços de convivência, inclusive os virtuais, a agressividade é um componente que não pode ser negado, mesmo que se apresente em formas disfarçadas de endereçamento ao outro. Ao conceber os componentes inclassificáveis do psiquismo humano, a psicanálise tomará as contribuições sobre, mais especificamente, os domínios não domesticáveis do inconsciente, bem como a pulsão de morte junto aos impulsos destrutivos encontrados nos sujeitos. Essa caracterização dos componentes destrutivos como constituintes do psiquismo amplia a discussão na medida em que não se pode desprezar as cotas de satisfação dos sujeitos em suas afiliações na relação eu/outro.

\footnotetext{
Na psicanálise, a violência é vista sempre em um referencial que mostra que o encontro com a linguagem não é sem consequências para o humano. Compreender a violência por meio desse ensino supõe adentrar-se na constituição do laço social, considerar os discursos que imperam em dado contexto histórico e não perder de vista as formas como os sujeitos são capazes de responder aos mesmos, já que a pulsão está presente também em momentos pacíficos. Com referência à agressividade, tanto Freud quanto Lacan situam-na como constitutiva do eu, na base da constituição do eu e na sua relação com seus objetos. Não negam sua existência, ao contrário, afirmam a agressividade na ordem humana, ordem libidinal. (FERRARI, 2006, p. 51).
}

No presente trabalho, a consideração acima acerca da agressividade humana para com seus semelhantes será útil, justamente para a compreensão da natureza da dificuldade de um relacionamento limpo, voltado para o progresso e totalmente disposto ao bem comum. Assim, as discussões existentes nas redes sociais não estão separadas dos próprios conflitos entre os sujeitos, reatualizando as condições históricas, econômicas e sociais, além dos próprios traços destrutivos encontrados no psiquismo.

\section{POLÊM!CA $\mid$ LABORE}

Polêmica - Revista Eletrônica da Uerj - Rua São Francisco Xavier, 524, $1^{\circ}$ andar bloco D, sl.1001 • Tels.: +55 21 2334-4088 / 4087 • http://www.e-publicacoes.uerj.br/index.php/polemica/index http://www.labore.uerj.br • laboreuerj@yahoo.com.br 


\section{A ciência como local de respostas}

A ciência, bem como o que se produz a partir dela, vem apresentando instrumentos e intervenções capazes de fornecer balizas e ferramentas para os sujeitos. E com o advento de novos artifícios tecnológicos no cotidiano, os sentidos atrelados ao progresso e seus efeitos no plano do viver tornaram-se objetos de participação ativos no contexto social. Ou seja, o que se compreende por ciência e seus representantes possuem grande importância nas formas de organização, julgamento e dos métodos pelos quais as apostas tanto individuais quanto coletivas se organizam. Tais desígnios da ciência também operam a partir de ferramentas, comumente atrelados ao funcionamento da vida cotidiana, como as funções desempenhadas por apetrechos tecnológicos, por exemplo. E desse modo, ao pensar nos efeitos da ciência enquanto um lugar privilegiado, esta via de pensamento priorizará os poderes e promessas depositados nesse significante.

Porém, a aposta em relação ao que se considera científico também é constituída por efeitos colaterais, principalmente no contraste que diz respeito aos ideais de uma vida mais "harmoniosa" e desprovida de conflitos, revelando alguns paradoxos sobre o poderio da ciência enquanto um organizador:

\footnotetext{
Durante as últimas gerações, a humanidade efetuou um progresso extraordinário nas ciências naturais e em sua aplicação técnica, estabelecendo seu controle sobre a natureza de uma maneira jamais imaginada. [...] Os homens se orgulham de suas realizações e têm todo o direito de se orgulharem. Contudo, parecem ter observado que o poder recentemente adquirido sobre o espaço e o tempo, a subjugação das forças da natureza, consecução de um anseio que remonta a milhares de anos, não aumentou a quantidade de satisfação prazerosa que poderiam esperar da vida e não nos tornou mais felizes. (FREUD, 1930/1996, p. 94).
}

Carvalho (2011) discute a posição da ciência enquanto um discurso destinado a dissecar, a ser capaz de responder e, principalmente, capaz de intervir nas aflições humanas. $\mathrm{O}$ fruto dessa complexa rede de conhecimentos e lugares privilegiados de fala traz consigo uma das gêneses dessa problemática: o lugar ocupado pelo especialista. Como destacado por Carvalho (2011), esse será dotado de saber suficiente para dizer o que é o certo e como fazê-lo, além de organizar os imperativos científicos atrelados ao capitalismo sobre as diretrizes do viver, constituindo outras ordens colaterais, como a epidemia de crianças medicalizadas em idade escolar e o disparate do uso de psicotrópicos na população geral.

$\mathrm{Na}$ convivência com as eficácias e novas roupagens que possibilitaram a entrada do discurso da ciência nas subjetividades, outro aspecto paradoxal às promessas de consecutivos

\section{POLÊM!CA $\mid$ LABORE}

Polêmica - Revista Eletrônica da Uerj - Rua São Francisco Xavier, 524, $1^{\circ}$ andar bloco D, sl.1001 • Tels.: +55 21 2334-4088 / 4087 • http://www.e-publicacoes.uerj.br/index.php/polemica/index http://www.labore.uerj.br • laboreuerj@yahoo.com.br 
progressos fez-se presente e esse poderio demonstrou o seu preço: o espaço narrativo do sujeito vem se tornando cada vez mais escasso diante de discursos e ferramentas que se colocam a responder pelos indivíduos.

Esta visão dos efeitos da ciência não caracteriza uma indisposição aos avanços trazidos por ela, mas antes, alerta da eficácia garantida aos avanços e respostas rotuladas como científicas, principalmente em termos de apaziguamento das angústias e medidas contra a condição de vulnerabilidade humana. Em última análise, tal estatuto pode vir a ocupar um lugar de fornecimento aos mais diversos tipos de anseio, em que até aquilo que concerne ao irrespondível torna-se passível de resposta e intervenção. E no caso das drogas ilícitas, a questão amplia-se para além daquilo que, cientificamente, pode ser considerado como benéfico ou danoso ao organismo humano, ao se tratar de questões políticas e de ordem econômica que envolvem as drogas consideradas ilegais.

\begin{abstract}
Drogas, tóxicos, narcóticos, entorpecentes, são diferentes nomenclaturas imprecisas para designar substâncias de circulação proibida em nossa legislação. Considerando que muitos medicamentos são distribuídos pelas chamadas "drogarias", podemos observar que, ao contrário da nomenclatura policialesca, a palavra droga significa, no plano médico, aquilo que chamamos de remédio. [...] e, por fim, narcóticos e entorpecentes são designados genericamente como drogas ilegais, embora não haja consenso no seu significado. Estas más aplicações, que reúnem as drogas ilícitas sob nomenclaturas imprecisas, devem parte de sua existência a práticas e atos classificatórios que se reproduzem, mas que também, da perspectiva política, acabam cumprindo uma função importante, que consiste em condensar em um único bloco substâncias que são alvo de perseguição governamental. Assim, o inimigo fica agrupado, fato que torna mais simples a declaração de guerra às drogas. (RODRIGUES apud ZACCONE, 2007, p. 39).
\end{abstract}

Como exposto na citação acima, a discussão das drogas consideradas ilícitas envolve diversos fatores que formam as representações e tratamentos legais acerca de uma substância taxada como ilegal. Dessa forma, o uso e valorização de enunciados apreciados como científicos necessitam de cuidados, mais especificamente, com quais finalidades "o nome da ciência" é mencionado em um tema de debate secular (o uso e comércio da maconha) no Brasil.

Com fins ilustrativos, o recorte abaixo pode ajudar a esclarecer o uso de impressões tidas como cientificamente validadas, sendo o locutor descrito como um político conservador e declaradamente contra a descriminalização da maconha no Brasil. Flávio Bolsonaro, em uma matéria para o jornal "O Globo" (2015), afirma:

Os benefícios de determinada substância extraída da Cannabis não se confundem com o uso terapêutico da maconha fumada. Tentar ludibriar a opinião pública com essa

\title{
POLÊM!CA $\mid$ LABORE
}

Polêmica - Revista Eletrônica da Uerj - Rua São Francisco Xavier, 524, $1^{\circ}$ andar bloco D, sl.1001 • Tels.: +55 21 2334-4088/4087 • http://www.e-publicacoes.uerj.br/index.php/polemica/index http://www.labore.uerj.br • laboreuerj@yahoo.com.br 
falácia é má-fé e atende a interesses menores, e não aos de pessoas doentes, que só conseguem melhorar seus quadros clínicos com o uso dessa substância. E, obviamente, ela não é administrada mediante o fumo. Se a pessoa acredita que não sofre nenhuma sequela pelo uso da maconha, é porque nunca refletiu sobre como estaria muito melhor se não o fizesse. Quem diz não sou eu, é a medicina. (OUTRA OPINIÃO; BOLSONARO, 2015).

Atentando ao último enunciado do recorte acima: "Quem diz não sou eu, é a medicina”, percebe-se claramente o uso do significante medicina a fim de corroborar em uma argumentação que não deixa mais espaços para o diálogo. Apesar de suas prerrogativas serem facilmente questionáveis quando comparadas em um espaço científico de discussão, a lógica que se instaura no texto, bem como seus efeitos, parte de outra ordem. É como se colocasse em jogo, esgotados todos os seus outros argumentos (criminais e sociais), ou ainda com a intenção de retificá-los, o seguinte imperativo: em última análise encontra-se a medicina, não sou eu quem está dizendo, mas ela.

No percurso desse estudo, não se propõe a discutir em profundidade os efeitos e meandros da ciência enquanto artifício capaz de modificar as relações de compreensão acerca de um objeto. Não se trata, como poderá ser visto adiante, do que é feita a ciência ou do que se trata a experiência de um especialista, mas, antes, das formas em que os enunciados atrelados ao científico são usados. Ou seja, a questão não se direciona para a essência das informações, mas sim, para o que se faz dela.

As descobertas e transmissões do conhecimento científico são importantes no processo de tomada de decisões, principalmente àquelas que concernem ao coletivo. Desse modo, podese compreender que o estatuto do que se mostra enquanto produto da ciência necessita igualmente de análises e críticas em seus contornos éticos, já que possibilita a tomada de decisões de forma mais guiada pela via racional, tal como uma baliza para temas complexos que envolvem a vida coletiva e individual.

Está claro para todos que os problemas éticos apontados pelo conhecimento científico na sua relação com o senso comum dizem respeito às aplicações desses conhecimentos, e seus efeitos sobre o mundo, sobre o homem (não somente os medicamentos, a biogenética ou os meios de morte [...]). Os problemas dessa natureza se multiplicam atualmente e sua importância é crucial para o mundo de amanhã. Eles testemunham visivelmente o vínculo que existe entre os conteúdos dos conhecimentos científicos, o pensamento científico e as outras dimensões do pensamento e das atividades humanas nas quais o senso comum ainda tem um papel mais direto. Eles mostram como o pensamento racional e que visa a objetividade é inseparável da vontade e de escolhas éticas, seja na unidade singular dos espíritos individuais ou nas coletividades sociais. (PATY, 2003, p. 22).

\section{POLÊM!CA $\mid$ LABORE}

Polêmica - Revista Eletrônica da Uerj - Rua São Francisco Xavier, 524, $1^{\circ}$ andar bloco D, sl.1001 • Tels.: +55 21 2334-4088/4087 • http://www.e-publicacoes.uerj.br/index.php/polemica/index http://www.labore.uerj.br • laboreuerj@yahoo.com.br 


\section{Metodologia}

Duas postagens foram destacadas para análise a partir do referencial da Análise do Discurso e da noção de "Frases sem Texto", proposta por Dominique Maingueneau (2014). As postagens foram escolhidas de acordo com os seguintes critérios: ser veiculada em páginas com interesses e posicionamentos ideológicos demarcados e possuir enunciados constituídos de noções consideradas oriundas da ciência. Ambos os materiais foram veiculados no ano de 2017 e tratam da maconha com variações entre si, tendo como ponto de semelhança o processo de discussão da sua descriminalização no país.

O quesito de comparação entre as duas postagens se dá, portanto, em termos de oposição política e de interesses que norteiam a temática da descriminalização da maconha, atualmente. A observação, nesse caso, possui primazia nas ilustrações que consideram os usuários de maconha e THC e, em especial, aos conjuntos de oposições e possíveis rivalidades encontradas entre os dois grupos (defensores da descriminalização e os proibicionistas). Tratando-se de aspectos subjetivos de atribuição de sentido e localizações destinadas a grupos distintos, o fator da rivalidade e da desvalorização apresenta-se como preponderante, se comparado a processos averiguatórios de ordem numérica referentes ao alcance de cada publicação.

Inicialmente, as análises se constituem a partir das naturezas dos destacamentos em cada um dos enunciados, podendo se tratar de dois tipos: forte e fraco. A diferenciação entre os tipos de destacamento acontece na relação de disponibilidade do seu texto-fonte, em conjunto com a possibilidade de o leitor ter acesso ao conteúdo original:

\footnotetext{
A frase que é destacada de um texto pode muito bem permanecer em sua vizinhança, assim, deve-se distinguir entre um destacamento forte, que implica uma separação do texto-fonte, e um destacamento fraco em que a frase destacada fica contígua ao textofonte. (MAINGUENEAU, 2014, p. 18, grifos do autor).
}

A partir dos destacamentos dos enunciados, sua natureza também será analisada em suas duas formas, a aforização primária e a secundária. A aforização primária não necessariamente é oriunda de um destacamento efetuado em algum texto de origem, já a secundária é originada de um destacamento exercido sobre algum texto-fonte. As diferenças entre ambas se tornam mais evidentes no decorrer da análise das postagens, adiante.

A enunciação aforizante obedece a uma economia diferente da do texto. Enquanto o texto resiste à apropriação por uma memória, a enunciação aforizante se dá imediatamente como memorável e memorizável. Não é a articulação de pensamentos de um ou de vários locutores por meios de diversos modos de organização textual,

\section{POLÊM!CA $\mid$ LABORE}

Polêmica - Revista Eletrônica da Uerj - Rua São Francisco Xavier, 524, $1^{\circ}$ andar bloco D, sl.1001 • Tels.: +55 21 2334-4088/4087 • http://www.e-publicacoes.uerj.br/index.php/polemica/index http://www.labore.uerj.br • laboreuerj@yahoo.com.br 
mas a expressão de uma convicção posta absolutamente [...] (MAINGUENEAU, 2014, p. 28).

As formas de destacamento de uma frase, bem como os efeitos que ela pretende gerar, tratam-se primordialmente dos realces destinados a um tema ou personagem. Conjuntamente ao processo de análise das postagens, os componentes de rivalidade e aspectos que podem ser considerados como agressivos em relação ao trato entre sujeitos e grupos são discutidos a partir de contribuições psicanalíticas, considerando os modos pelos quais uma informação pode ser temperada por finalidades que escapam às intenções conscientes. Dessa forma, os modos de discussão acerca de um tema frequentemente disseminado por canais de comunicação apresentam traços que se entrelaçam em diversos caminhos. Seu trajeto mostra-se como um emaranhado de fatores e mecanismos, desde estudos e entrevistas até os meios de divulgação fora do círculo científico.

\section{Análise das postagens}

A primeira postagem selecionada refere-se à página Conservador que possui como descrição a seguinte frase: "a página Conservador é uma página que fala sobre política, polícia e outras questões relevantes para a sociedade...".

Figura - 1: Postagem da página “Conservador”

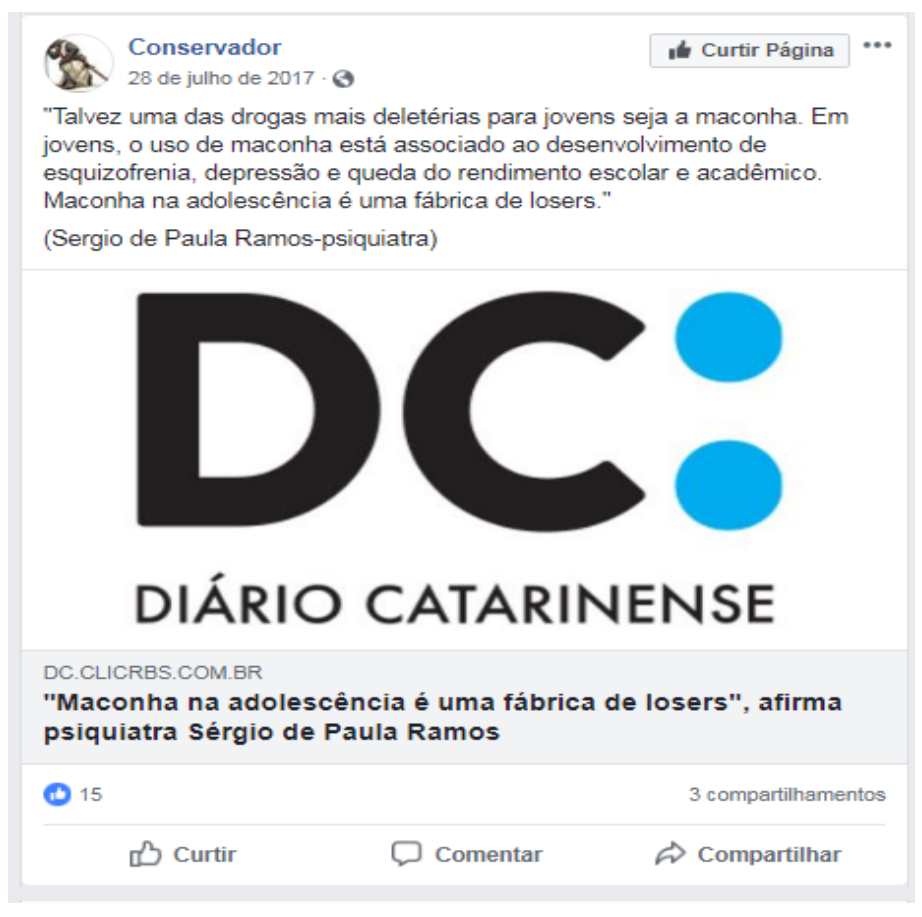

\section{POLÊM!CA | LABORE}

Polêmica - Revista Eletrônica da Uerj - Rua São Francisco Xavier, 524, $1^{\circ}$ andar bloco D, sl.1001 • Tels.: +55 21 2334-4088/4087 • http://www.e-publicacoes.uerj.br/index.php/polemica/index http://www.labore.uerj.br • laboreuerj@yahoo.com.br 
Fonte: Conservador, 2017.

Legenda: “"Talvez uma das drogas mais deletérias para jovens seja a maconha. Em jovens, o uso de maconha está associado ao desenvolvimento de esquizofrenia, depressão e queda do rendimento escolar e acadêmico. Maconha na adolescência é uma fábrica de losers' (Sergio de Paula Ramos-psiquiatra)".

No caso dos enunciados destacáveis, percebe-se uma função em recortar uma parte da fala do locutor em detrimento do restante do conteúdo em que a frase se deu. Na Figura 1, a frase destacada do psiquiatra Sérgio Ramos foi selecionada para a chamada da entrevista. Tal recorte, segundo Maingueneau (2014), é fortemente usado nos meios jornalísticos e atualmente, também se encontram nos veículos da internet que se propõem à comunicação. Assim, os destacamentos são capazes de fornecer ganchos para o conteúdo que fazem referência, ao mesmo tempo em que podem salientar indicativos que fogem ao contexto em que foram gerados.

Vê-se facilmente em que repousa essa sensação de destacabilidade: trata-se de enunciados que se dão como autônomos, de um ponto de vista textual (não há nenhuma necessidade de considerar o que precede e o que segue para compreendêlos). (MAINGUENEAU, 2014, p. 14).

Paradoxalmente aos interesses políticos e sociais da página Conservador, Sérgio Ramos afirma no conteúdo publicado pelo Diário Catarinense (ROSO, 2017) ter um posicionamento contrário ao dos movimentos de internação compulsória na Crackolândia em São Paulo. O álcool foi duramente criticado por Ramos, que chega a afirmar:

Sinto alguma frustração em perceber que, no Brasil, quem faz a política sobre drogas é a indústria. A primeira droga que o brasileiro usa, e lamentavelmente cada vez mais cedo, é o álcool. Uma criança que toma álcool aos 12, 13 anos vai experimentar maconha aos 14 e, aos 17, está na cocaína ou em drogas sintéticas. Está muito claro que se deve começar por uma política restritiva do álcool. Calcula-se que $8 \%$ do faturamento da indústria da cerveja provém da venda para menor de idade. Então, não se espere que a indústria seja aliada na erradicação do consumo de bebidas alcoólicas por menores. Não conseguimos mobilizar a opinião pública para se opor à indústria do álcool, poderosa, que está sempre mancomunada com a turma da publicidade, com os donos das grandes empresas de comunicação. Proibimos a propaganda do tabaco e deu certo. A propaganda de bebida é toda voltada para o público jovem. Você não vê velho tomando cerveja, você vê jovem, bonito, forte em situação lúdica, praia, festa. Isso vai incutindo na população jovem e de adultos, de modo geral, que não existe a possibilidade de divertimento sem álcool. Negando que, nos levantamentos nacionais, $48 \%$ da população adulta não bebe. Colocam na nossa cabeça que todo mundo bebe. (ROSO, 2017).

O que chama atenção no contexto da entrevista é justamente o protagonismo que a maconha ganha em detrimento das diversas drogas citadas pelo entrevistado. Deve-se salientar

\section{POLÊM!CA $\mid$ LABORE}

Polêmica - Revista Eletrônica da Uerj - Rua São Francisco Xavier, 524, $1^{\circ}$ andar bloco D, sl.1001 • Tels.: +55 21 2334-4088 / 4087 • http://www.e-publicacoes.uerj.br/index.php/polemica/index http://www.labore.uerj.br • laboreuerj@yahoo.com.br 
o contexto político e social em que o destacamento acontece, já que a discussão em torno do uso medicinal da maconha abriu diversas possibilidades de diálogos visando a sua descriminalização. De acordo com o site do Senado Federal (2017), a Comissão de Direitos Humanos (CDH) e Legislação Participativa aprovou encaminhamento do relatório que visa a descriminalização do uso da maconha para fins medicinais, sinalizando, assim, um avanço burocrático dentro do Senado, podendo viabilizar uma mudança no estatuto legal do consumo da cannabis.

Portanto, a escolha pelo objeto "maconha" em detrimento de outras drogas, bem como a ênfase dada para a frase "maconha na adolescência é uma fábrica de losers" seguem acordos calcados por interesses que não necessariamente estão alinhados totalmente com a universalidade dos temas tratados pelo texto-fonte.

Sendo assim, a primazia de escolha pela maconha enquanto objeto de destaque na entrevista e os efeitos gerados por esse enunciado evidenciam a natureza do destacamento que, como visto, segundo Maingueneau (2014), pode ser considerado como forte ou fraco. $\mathrm{Na}$ Figura 1, relativa à postagem da página “Conservador”, trata-se de um destacamento fraco, em que o acesso ao texto-fonte aparece como uma possibilidade direta ao leitor. Tratando-se da natureza do enunciado, bem como das condições em que foi destacado, pode ser tratada como uma aforização secundária (MAINGUENEAU, 2014), essa que poderá ser evidenciada e gerar efeitos descolados de seu texto de origem ao atuar junto do enunciador.

A segunda publicação dessa análise pertence à página Quebrando o Tabu, possuindo como descrição a seguinte frase: "por um mundo mais bem informado e menos careta".

\section{POLÊM!CA | LABORE}

Polêmica - Revista Eletrônica da Uerj - Rua São Francisco Xavier, 524, $1^{\circ}$ andar bloco D, sl.1001 • Tels.: +55 21 2334-4088/4087 • http://www.e-publicacoes.uerj.br/index.php/polemica/index http://www.labore.uerj.br • laboreuerj@yahoo.com.br 
Figura - 2: Postagem da página "Quebrando o Tabu"

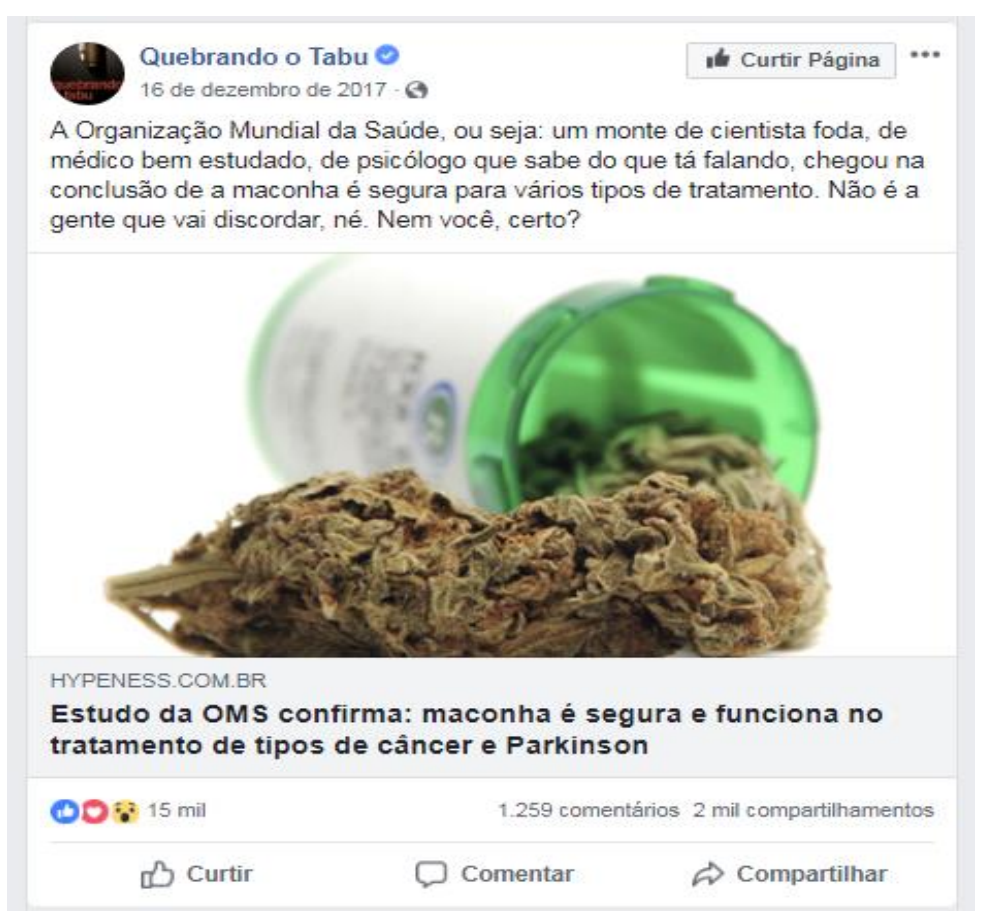

Fonte: Quebrando o Tabu, 2017.

Legenda: "A Organização Mundial da Saúde, ou seja: um monte de cientista foda, de médico bem estudado, de psicólogo que sabe do que tá falando, chegou na conclusão de a maconha é segura para vários tipos de tratamento. Não é a gente que vai discordar, né. Nem você, certo?".

A publicação possui um link do portal Hypeness que situa as declarações da Organização Mundial da Saúde acerca do Canabidiol, salientando os benefícios proporcionados pelo uso da maconha em alguns quadros clínicos como: epilepsia, câncer, Alzheimer e Parkinson. Por fim, a reportagem do portal Hypeness finaliza o texto com a seguinte frase: "evidências recentes de estudos com animais e humanos mostraram que o uso dela pode ter um grande valor terapêutico para pacientes vítimas de epilepsia ou condições relacionadas" (HYPENESS).

O interessante na matéria publicada, e posteriormente veiculada na página Quebrando o Tabu, é o fato de ambas não possuírem um link para o citado relatório da OMS. Buscas realizadas no Google com as seguintes palavras-chave: "relatório OMS canabidiol" resultaram em diversos estudos e matérias jornalísticas publicadas em outros portais de notícias como o Universo Online (UOL) e EBC - Agência Brasil. Assim, a natureza do destacamento proposto por Maingueneau (2014) encontra uma questão paradoxal na difusão pela página Quebrando o Tabu. Enquanto a relação entre o enunciado veiculado na página Quebrando o Tabu para a

\section{POLÊM!CA $\mid$ LABORE}

Polêmica - Revista Eletrônica da Uerj - Rua São Francisco Xavier, 524, $1^{\circ}$ andar bloco D, sl.1001 • Tels.: +55 21 2334-4088 / 4087 • http://www.e-publicacoes.uerj.br/index.php/polemica/index http://www.labore.uerj.br • laboreuerj@yahoo.com.br 
matéria em que ela se vincula pode ser considerada um destacamento fraco, a mesma condição não se aplica à ordem de disposição encontrada no texto-fonte. Na matéria veiculada no Hypeness, apesar de fazer menções integrais ao estudo distribuído pela OMS, não existe a possibilidade de contato com o material original, ou seja, o citado e repercutido relatório da Organização Mundial da Saúde não está disponível para o leitor. Essa segunda condição pode ser considerada um destacamento forte, esse que não se faz presente, de forma facilitada, para o leitor que acompanha o desenrolar dos enunciados.

No caso do enunciado veiculado na página Quebrando o Tabu, o material pode ser analisado como sendo uma "aforização primária" (MAINGUENEAU, 2014, p. 28) que não necessariamente resulta do destacamento de um texto. Outros exemplos de aforizações primárias são os slogans, adágios, provérbios e etc. A enunciação aforizante, salienta Maingueneau (2014), trabalha em uma lógica diferente do texto. Não se tratando de uma articulação de pensamentos, mas antes, se expressando em termos de convicção absoluta, atuando na ordem da afirmação e sentença.

Por último, é importante destacar que a matéria divulgada pelo portal Hypeness não possui informação de autoria. Nas publicações destacadas do Facebook (Figuras 1 e 2) a mesma situação ocorre. Não existe o rastro do moderador responsável pelos destacamentos e nos dois materiais é perceptível a não exposição dos respectivos autores das postagens. Enquanto na postagem $n^{\circ} 1$ tem-se uma colagem explícita da entrevista publicada, na postagem $n^{\circ} 2$ encontra-se um breve texto com vias a antecipar os resultados da pesquisa citada. Sobre as condições de autoria na internet, Maingueneau (2010), conforme citado por Moraes (2012, p. 945), discorre sobre as especificidades e responsabilizações do estatuto do autor nos espaços da internet:

Segundo Maingueneau (2010, p. 39), “o midium, no caso a internet, tem precisamente por efeito minar certas condições de acesso ao estatuto de auctor". Seguindo o raciocínio desse autor, devemos considerar que a proliferação de blogs, perfis etc. anula uma importante restrição a respeito da constituição de uma autoria plena: a raridade. [...] Além disso, outras modificações são decisivas, como o fato de que, na internet, não há necessidade de intermediários (como editores), sendo que a edição, ao mesmo tempo em que impõe uma séria restrição, funciona "implicitamente como certificação de qualidade" (MAINGUENEAU, 2010, p. 40). No entanto, a atribuição de relevância e a "certificação de qualidade" passam a ser medidas por razões de outra ordem, da qual o número de visitantes/seguidores é decisivo e provoca efeito em cadeia: um perfil muito visitado é tido como "bom" e, consequentemente, passa a ser ainda mais acessado.

\section{POLÊM!CA $\mid$ LABORE}

Polêmica - Revista Eletrônica da Uerj - Rua São Francisco Xavier, 524, $1^{\circ}$ andar bloco D, sl.1001 • Tels.: +55 21 2334-4088/4087 • http://www.e-publicacoes.uerj.br/index.php/polemica/index http://www.labore.uerj.br • laboreuerj@yahoo.com.br 
Os conteúdos veiculados no espaço da internet, a partir das peculiaridades já discutidas, tendem a apresentar diferenças no fluxo de informações do jornalismo convencional. Porém, os critérios de manejo das formas de ilustração sobre temas considerados polêmicos ainda se mantém a partir recortes e edições que podem ser utilizadas com diferentes finalidades. Assim, a internet também se apresenta como um lugar de embate entre grupos que, misturando-se aos conteúdos voltados para a informação, agrega possibilidades de direcionamentos e contato entre os sujeitos.

\section{O lugar do outro: rivalidades e ataques}

Retornando à ideia em que o sujeito é pensado a partir de sua composição com a agressividade constituinte, bem como a (possível) inexistência de um posicionamento totalmente voltado para o bem comum e com finalidades pacíficas (FREUD, 1930/1996), a agressividade passa ser a compreendida nos enunciados analisados como uma representação e atualização do conflito no espaço das redes sociais.

Em uma outra análise, na condição do diálogo, ou seja, tomando as duas postagens como possibilidades de cruzamentos políticos, ideológicos e sociais, percebe-se um conflito que se instaura na localização do outro, aquele(s) cuja opinião pode diferir da proposta pela página.

\footnotetext{
Postagem $\mathrm{N}^{\circ}$ 1: "Talvez uma das drogas mais deletérias para jovens seja a maconha. Em jovens, o uso de maconha está associado ao desenvolvimento de esquizofrenia, depressão e queda do rendimento escolar e acadêmico. Maconha na adolescência é uma fábrica de losers (Sergio de Paula Ramos - psiquiatra)". (CONSERVADOR, 2017).

Postagem N²: "A Organização Mundial da Saúde, ou seja: um monte de cientista foda, de médico bem estudado, de psicólogo que sabe do que tá falando, chegou na conclusão de a maconha é segura para vários tipos de tratamento. Não é a gente que vai discordar, né [?]. Nem você, certo?". (QUEBRANDO O TABU, 2017).
}

$\mathrm{Na}$ postagem número um, percebe-se o uso da palavra loser, que traduzido para o português significa perdedor e/ou fracassado. Juntamente a outras colocações, como a queda do rendimento escolar e o desenvolvimento de doenças mentais, tal enunciado expõe uma relação de inferioridade e predisposição a efeitos indesejáveis nos usuários de maconha. Portanto, o que se mostra em jogo é a suposta inferioridade daqueles que usam maconha em comparação aos que não fazem uso da mesma. Somado ao conteúdo veiculado na página

\section{POLÊM!CA $\mid$ LABORẸ}

Polêmica - Revista Eletrônica da Uerj - Rua São Francisco Xavier, 524, $1^{\circ}$ andar bloco D, sl.1001 • Tels.: +55 21 2334-4088/4087 • http://www.e-publicacoes.uerj.br/index.php/polemica/index http://www.labore.uerj.br • laboreuerj@yahoo.com.br 
Conservador, tem-se a atualização de uma disputa social, política e econômica entre sujeitos usuários e não usuários, onde um lado do conflito pode ser taxado como doente e improdutivo.

Já na postagem número dois, esse conflito mostra-se, aparentemente, de forma mais sofisticada. Ao invocar lugares de saber e de detenção da práxis saúde-doença, a página Quebrando o Tabu salienta tais prestígios com as colocações "foda”, "bem estudado" e "sabe do que tá falando". O confronto estabelecido pela página nas condições de um diálogo com opositores dá-se por um apagamento das opiniões contrárias, ou seja, seu ponto de conflito não se dá pela valorização do lugar de saber, propriamente, mas no rebaixamento das possíveis colocações contrárias expressa na pergunta final: "não é a gente que vai discordar, né [?]. Nem você, certo?”. Assim, o leitor que se considerar contrário ao conteúdo veiculado terá que correr o risco de ser "apagado" pelas considerações advindas dos "fodas" e de quem "sabe do que está falando". Ou seja, o lugar da oposição nesse contexto passará propriamente por não ser "foda" (ou digno de respeito em suas colocações) e de não saber do que se trata, gerando o efeito de incapacitar os opositores de participar no debate.

Apesar de roupagens que podem ser disfarçadas em supostas preocupações com a saúde da população, evidentes em ambas as postagens analisadas, o que se mostra como um fator preponderante é o próprio desejo de aniquilação do espaço de fala do outro, esse que pode tanto ser taxado de doente e fracassado, como um sujeito desprovido de conhecimento, portanto, passível de silenciamento. Nesse ponto, o olhar se volta para as possíveis intenções implícitas em cada um dos enunciados, notando a agressividade e seus desdobramentos nas relações humanas.

O elemento de verdade por trás disso tudo, elementos que as pessoas estão tão dispostas a repudiar, é que os homens não são criaturas gentis, que desejam ser amadas e que, no máximo, podem defender-se quando atacadas; pelo contrário, são criaturas entre cujos dotes instintivos deve-se levar em conta uma poderosa quota de agressividade [...] Em circunstâncias que lhes são favoráveis, quando as forças mentais contrárias que normalmente a inibem se encontram fora de ação, ela também se manifesta espontaneamente e revela o homem como uma besta selvagem, a quem a consideração para com sua própria espécie é algo estranho. (FREUD, 1930/1996, p. 116).

\section{Sobre a divulgação de dados científicos em mídias}

Mais especificamente na postagem $n^{\circ} 2$, que estabelece uma relação direta com uma pesquisa, pode-se vislumbrar o poderio argumentativo dos dados científicos em termos de impacto. O que chama a atenção nesse ponto é justamente a modulação que se manifesta

\section{POLÊM!CA $\mid$ LABORE}

Polêmica - Revista Eletrônica da Uerj - Rua São Francisco Xavier, 524, $1^{\circ}$ andar bloco D, sl.1001 • Tels.: +55 21 2334-4088 / 4087 • http://www.e-publicacoes.uerj.br/index.php/polemica/index http://www.labore.uerj.br・ laboreuerj@yahoo.com.br 
independentemente das pesquisas, visto que, antes, tais dados são utilizados como acessórios e chamarizes para a efetivação de um posicionamento anterior. Nesse ponto, Vilela-Ardenghi (2011) a partir dos trabalhos de Foucault (1971), salienta que “[...] a vontade de verdade — em nossa sociedade - exerce uma certa pressão sobre outros discursos, o que tem como um de seus efeitos a recorrência a enunciados de verdade ainda que não se esteja no interior do campo que os produziu” (FOUCAULT, 1971 apud VILELA-ARDENGUI, 2011, p. 46).

Atrelado a uma suposta resposta de pesquisa o arsenal da ciência é evocado em uma disputa moral, produzindo um efeito de validação que pode ser acrescentado às prerrogativas de cada página. Sobressaindo, dessa forma, um anseio expresso nas duas postagens em forma de clamor ao "verdadeiro", ao dado científico e às experiências de profissionais da área da saúde. Curiosamente, ambas as reportagens não possuem referências científicas brutas (publicações que disponibilizem os dados de forma integral) capazes de balizar e fornecer critérios de julgamento acerca do uso da maconha, ambos os exemplos utilizam o estatuto do científico sem, necessariamente, ser. Nesse estudo, evidencia-se o tom apelativo aos lugares de saber como detentores de um "argumento final", junto aos dados e veredictos chancelados por aqueles que os esboçam. No caso da postagem $\mathrm{n}^{\circ} 1$, esse aspecto fica salientado pelo lugar de saber ocupado pelo psiquiatra entrevistado pelo Diário Catarinense. Já na postagem $n^{\circ} 2$, a chamada utilizada pela página Quebrando o Tabu invoca, de forma similar, o aspecto irrefutável dos lugares de saber ocupados pelos profissionais da saúde.

Sobre a diferença entre a discussão no ambiente acadêmico e a veiculação de dados e inovações científicas em veículos de comunicação comuns, Charaudeau (2016) salienta que o processo de divulgação de dados científicos leva a repensar a modelagem ocasionada pelas mídias de informação, em que o discurso de divulgação não é a tradução de um discurso científico, mas sim um discurso construído por um órgão midiático em função da finalidade de seu contrato de comunicação.

A finalidade se caracteriza por uma dupla visada: de informação e de captação. A visada de informação consiste em transmitir ao outro, o cidadão, um saber que ele supostamente ignora. Mas esta visada não se destina exatamente a fazer o destinatário a adquirir um saber, como no caso da situação de ensino, mas a lhe permitir formar uma opinião. Para que esse ato se justifique, é preciso que o saber em questão possa ser reconhecido como verdadeiro. A visada de informação obriga a "dizer a verdade", não uma verdade que pretende ser $a$ verdade, mas uma verdade que seja verossímil. As mídias de informação têm, assim, que responder a uma questão de credibilidade, o que as conduzem a empregar estratégias de autenticação dos fatos com a ajuda de testemunhos e de documentos; de revelação, com a ajuda de entrevistas, de enquetes

\section{POLÊM!CA $\mid$ LABORE}

Polêmica - Revista Eletrônica da Uerj - Rua São Francisco Xavier, 524, $1^{\circ}$ andar bloco D, sl.1001 • Tels.: +55 21 2334-4088/4087 • http://www.e-publicacoes.uerj.br/index.php/polemica/index http://www.labore.uerj.br • laboreuerj@yahoo.com.br 
ou de debates; de explicação sobre o porquê e o como do acontecimento. (CHARAUDEAU, 2016, p. 552, grifos do autor).

\section{Conclusão}

Desde sua chegada ao Brasil, passando por processos de popularização e combate repressivo ao seu uso, a maconha encontra-se sempre em meio aos discursos que se colocam como capazes de discorrer sobre seus efeitos. Atualmente, com o advento e disseminação da internet como um meio de comunicação massificado, a discussão permanece e se sobressai como um assunto mobilizador e democrático: todos, independentemente de posição política, conservadores e liberais, podem expressar em suas páginas as considerações que julgam pertinentes sobre a maconha.

Conclui-se que a discussão virtual em torno dos benefícios e possível malefício da maconha encontra-se em um terreno mais político e moral do que científico (apesar da impossibilidade de dissociação plena entre esses componentes), justamente pelas apropriações utilizadas por ambos os grupos - os proibicionistas e os favoráveis à descriminalização. As posições de conhecimento ganham status na medida em que seus detentores são convocados a falar sobre o assunto, deliberando lugares, permissivos ou não, facilmente utilizáveis como um argumento último, no que tange aos assuntos da saúde e reações corporais.

Como tratado na segunda seção do texto, o discurso científico como um lugar de saber pronto a responder aos anseios da sociedade é questionável, antes de tudo pela própria instabilidade daquele que anseia, ou seja, dos próprios sujeitos que buscam aparos nesse meio para balizar seus desejos e escolhas no repertório social. Conjuntamente, os interesses, disputas e domínios sobre a questão da maconha no país formam um complexo enredo, lugar em que os especialistas e figuras de autoridade sobre o tema são chamados a discorrer e, de algum modo, fornecer tessituras para argumentos capazes de habitar os lados de uma oposição.

Por fim, as análises dos exemplos utilizados para o estudo demonstram que as formas e componentes de veiculação dos resultados de uma pesquisa, bem como as impressões e experiências de profissionais da área da saúde relacionados ao tema, podem ser utilizados de modo mais conflituoso do que, de fato, promover trocas e fomentar o debate acerca da maconha. Esse efeito não é necessariamente oriundo da fonte em que foram gerados, mas partem, em grande medida, dos interesses do enunciador que a veicula. Assim, torna-se evidente que as

\section{POLÊM!CA | LABORE}

Polêmica - Revista Eletrônica da Uerj - Rua São Francisco Xavier, 524, $1^{\circ}$ andar bloco D, sl.1001 • Tels.: +55 21 2334-4088/4087 • http://www.e-publicacoes.uerj.br/index.php/polemica/index http://www.labore.uerj.br • laboreuerj@yahoo.com.br 
formas de tratamento ao(s) outro(s), bem como os lugares destacados em oposições políticas e ideológicas, não se disfarçam à luz da agressividade invocada em um conflito.

Essa mesma agressividade que consiste em um fator e componente intrínseco dos processos de socialização e das formas de articulação dos afetos, apesar da impossibilidade de ser exterminado do componente humano, possui formas de simbolização. "Existe a agressividade, mas ela pode ser sublimada, pode ser recalcada, não precisa ser atuada, pois o humano conta com o recurso da palavra, da mediação simbólica (FERRARI, 2006, p.51)”. Ou seja, faz-se necessário que o encontro com a alteridade aconteça no nível do diálogo, levando em consideração a complexidade do tema e as disputas intrincadas no uso e comércio de drogas ilícitas, em especial nesse trabalho, da situação da maconha e seus componentes.

Em meio ao complexo enredo e mistificações sobre os usos possíveis da maconha, podese usar como exemplo o caso da ovelha Dolly (o primeiro mamífero clonado com sucesso a partir de uma célula adulta), no qual cientistas e profissionais especializados em reprodução foram recrutados no mundo todo para falar sobre o assunto e, ao mesmo tempo, responder aos temores e curiosidades da sociedade. Sobre as formas de ilustração e narrativas destinadas ao caso de clonagem, Charaudeau (2016, p. 555) afirma: "há modos e modos de se fotografar a ovelha Dolly". Sobre as drogas, ilícitas ou não, e no caso específico da maconha, torna-se possível parafrasear com o tema: há modos e modos de se fotografar e discutir socialmente as drogas.

\section{Referências}

AGÊNCIA SENADO. Cultivo de maconha para fins medicinais avança no Senado. Brasília, 15 dez. 2017. Disponível em: <https://www12.senado.leg.br/noticias/materias/2017/12/14/cultivo-de-maconha-para-finsmedicinais-avanca-no-senado>. Acesso em: $21 \mathrm{dez} .2018$.

BARROS, André; PERES, Marta. Proibição da maconha no Brasil e suas raízes históricas escravocratas. Revista Periferia, v. 3, n. 2, jul./dez. 2011. Disponível em: <https://www.epublicacoes.uerj.br/index.php/periferia/article/view/3953>. Acesso em: 30 dez. 2018.

CARLINI, E. A. A história da maconha no Brasil. Jornal Brasileiro de Psiquiatria, Rio de Janeiro, v. 55, n. 4, p. 314-317, 2006.

CARVALHO, S. M. A psicanálise e o discurso da ciência. 2011. 183 f. Tese (Doutorado em Psicologia Social) - Programa de Pós-Graduação em Psicologia, Instituto de Psicologia da Universidade de São Paulo, São Paulo, 2011.

CONSERVADOR. Talvez uma das drogas mais deletérias para jovens seja a maconha. Em jovens, o uso de maconha está associado ao desenvolvimento de esquizofrenia, depressão e queda do rendimento escolar e

\section{POLÊM!CA $\mid$ LABORE}

Polêmica - Revista Eletrônica da Uerj - Rua São Francisco Xavier, 524, $1^{\circ}$ andar bloco D, sl.1001 • Tels.: +55 21 2334-4088 / 4087 • http://www.e-publicacoes.uerj.br/index.php/polemica/index http://www.labore.uerj.br • laboreuerj@yahoo.com.br 
acadêmico. Maconha na adolescência é uma fábrica de losers (Sergio de Paula Ramos-psiquiatra). Brasil, 28 jul. 2017. Facebook: Conservador. Disponível em:

<https://www.facebook.com/conservador2016/posts/1917625851840383>. Acesso em: 30 dez. 2018.

COSTA, A. M. N. Sociabilidade virtual: separando o joio do trigo. Psicologia \& Sociedade, v. 17, n. 2, p. 5057, maio/ago. 2005.

CHARAUDEAU, P. Sobre o discurso científico e sua midiatização. Tradução de Maria Eduarda Giering e Luciana Cavalheiro. Calidoscópio, v. 14, n. 3, p. 550-556, set./dez. 2016.

CRIPPA, J. A; et al. Efeitos cerebrais da maconha - resultados dos estudos de neuroimagem. Revista Brasileira de Psiquiatria, São Paulo, v. 27, n. 1, p. 70-78, mar. 2005. DOI: 10.1590/S1516-44462005000100016.

EMPRESA BRASIL DE COMUNICAÇÂO. OMS divulga recomendação para não catalogar canabidiol como droga. EBC. Cidade do México, 15 dez. 2017. Disponível em:

$<$ http://agenciabrasil.ebc.com.br/internacional/noticia/2017-12/oms-divulga-recomendacao-para-nao-catalogarcanabidiol-como-droga/>. Acesso em: $30 \mathrm{dez} .2018$.

FERRARI, I. F. Agressividade e violência. Psicologia Clínica, Rio de Janeiro, v. 18, n. 2, p. 49-62, 2006.

FOUCAULT, M. A ordem do discurso (1971). São Paulo: Edições Loyola, 1996.

FREUD, S. O Mal-Estar na Civilização (1930). In: Edição standard brasileira das obras psicológicas completas de Sigmund Freud. Rio de Janeiro: Imago, 1996. V. 21. p. 81-148.

HYPENESS. Estudo da OMS confirma: maconha é segura e funciona no tratamento de tipos de câncer e Parkinson. Hypeness. Disponível em: <https://www.hypeness.com.br/2017/12/estudo-da-oms-confirmamaconha-e-segura-e-funciona-no-tratamento-de-tipos-de-cancer-e-parkinson/>. Acesso em: $30 \mathrm{dez} .2018$.

LIMA, N. L. O fascínio e a alienação no ciberespaço: uma perspectiva psicanalítica. Arquivos brasileiros de psicologia, Rio de Janeiro, v. 58, n. 2, p. 38-50, dez. 2006.

MAINGUENEAU, D. Doze conceitos em Análise do Discurso. São Paulo: Parábola, 2010.

Frases sem texto. Tradução de Sírio Possenti et al. 1. ed. São Paulo: Parábola Editorial, 2014.

MORAES, É. Mídias sociais, identidade e autoria. Estudos Linguísticos, São Paulo, v. 41, n. 3, p. 936-947, set./dez. 2012.

OUTRA OPINIÃO; BOLSONARO, F. Se a moda pega. O Globo. Rio de janeiro, 18 fev. 2015. Disponível em: <https://oglobo.globo.com/opiniao/se-moda-pega-15338819>. Acesso em: 21 abr. 2019.

PATY, M. A ciência e as idas e voltas do senso comum. Scientiae Studia, v. 1, n. 1, p. 9-26, mar. 2003.

QUEBRANDO O TABU. A Organização Mundial da Saúde, ou seja: um monte de cientista foda, de médico bem estudado, de psicólogo que sabe do que tá falando, chegou na conclusão de a maconha é segura para vários tipos de tratamento. Não é a gente que vai discordar, né. Nem você, certo? Brasil, 16 dez. 2017. Facebook: Quebrando o Tabu. Disponível em: <https://www.facebook.com/quebrandootabu/posts/a-

organiza\%C3\%A7\%C3\%A3o-mundial-da-sa\%C3\%BAde/1722996064423440>. Acesso em: 30 dez. 2018.

RODRIGUES, T. Narcotráfico: uma guerra na guerra. São Paulo: Desativo, 2003.

ROSO, L."Maconha na adolescência é uma fábrica de losers", afirma psiquiatra Sérgio de Paula Ramos. Diário Catarinense. Santa Catarina, 28 jul. 2017. Disponível em: <http://dc.clicrbs.com.br/sc/estilo-devida/noticia/2017/07/maconha-na-adolescencia-e-uma-fabrica-de-losers-afirma-psiquiatra-sergio-de-paularamos-9855388.html>. Acesso em: 30 dez. 2018.

\section{POLÊM!CA $\mid$ LABORE}

Polêmica - Revista Eletrônica da Uerj - Rua São Francisco Xavier, 524, $1^{\circ}$ andar bloco D, sl.1001 • Tels.: +55 21 2334-4088 / 4087 • http://www.e-publicacoes.uerj.br/index.php/polemica/index http://www.labore.uerj.br • laboreuerj@yahoo.com.br 
UNIVERSO ONLINE. Canabidiol, substância presente na maconha, não causa dependência, diz OMS. Universo Online. São Paulo, 14 dez. 2017. Disponível em:

<https://noticias.uol.com.br/saude/ultimasnoticias/redacao/2017/12/14/canabidiol-substancia-presente-namaconha-nao-causa-dependencia-dizoms.html/>. Acesso em: 30 dez. 2018.

VILELA-ARDENGHI, A. C. Turismo e ciência: reflexões em torno da produtividade do conceito foucaultiano de verdade para a AD. Percursos Linguísticos, Vitória (ES), v. 1, n. 1, p. 46-56, 2011.

ZACCONE, O. Acionistas do nada: quem são os traficantes de drogas. Rio de Janeiro: Revan, 2007.

Recebido em: 18/12/2018.

Aceito em: 30/12/2018.

\section{POLÊM!CA $\mid$ LABORE}

Polêmica - Revista Eletrônica da Uerj - Rua São Francisco Xavier, 524, $1^{\circ}$ andar bloco D, sl.1001 • Tels.: +55 21 2334-4088 / 4087 • http://www.e-publicacoes.uerj.br/index.php/polemica/index http://www.labore.uerj.br • laboreuerj@yahoo.com.br 